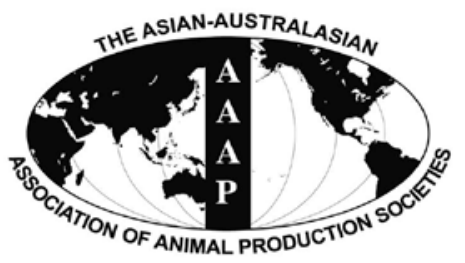

Asian-Aust. J. Anim. Sci.

Vol. 25, No. 1 : 98 - 103

January 2012

www.ajas.info

http://dx.doi.org/10.5713/ajas.2011.11201

\title{
Re-evaluation of the Optimum Dietary Vitamin C Requirement in Juvenile Eel, Anguilla japonica by Using L-ascorbyl-2-monophosphate
}

\author{
Jun-Young Bae ${ }^{1,4}$, Gun-Hyun Park ${ }^{1}$, Kwang-Yeol Yoo ${ }^{2}$, Jeong-Yeol Lee ${ }^{3}$, Dae-Jung Kim ${ }^{4}$ and Sungchul C. Bai ${ }^{1{ }^{*}}$ \\ ${ }^{1}$ Department of Marine Bio-materials and Aquaculture/Feeds and Foods Nutrition Research Center, \\ Pukyong National University, Busan, Korea
}

\begin{abstract}
This study was conducted to re-evaluate the dietary vitamin C requirement in juvenile eel, Anguilla japonica by using L-ascorbyl-2-monophosphate (AMP) as the vitamin C source. Five semi-purified experimental diets were formulated to contain 0 $\left(\mathrm{AMP}_{0}\right), 30\left(\mathrm{AMP}_{24}\right), 60\left(\mathrm{AMP}_{52}\right), 120\left(\mathrm{AMP}_{108}\right)$ and 1,200 ( $\left.\mathrm{AMP}_{1137}\right) \mathrm{mg} \mathrm{AMP} \mathrm{kg}{ }^{-1}$ diet on a dry matter basis. Casein and defatted fish meal were used as the main protein sources in the semi-purified experimental diets. After a 4-week conditioning period, fish initially averaging $15 \pm 0.3 \mathrm{~g}$ (mean $\pm \mathrm{SD}$ ) were randomly distributed to each aquarium as triplicate groups of 20 fish each. One of five experimental diets was fed on a DM basis to fish in three randomly selected aquaria, at a rate of $3 \%$ of total body weight, twice a day. At the end of the feeding trial, weight gain (WG) and specific growth rate (SGR) for fish fed $\mathrm{AMP}_{52}$ and $\mathrm{AMP}_{108}$ were significantly higher than those recorded for fish fed the control diet $(\mathrm{p}<0.05)$. Similarly, feed efficiency (FE) and protein efficiency ratio (PER) for fish fed $\mathrm{AMP}_{52}$ were significantly higher than those for fish fed the control diet $(\mathrm{p}<0.05)$. Broken-line regression analysis on the basis of WG, SGR, FE and PER showed dietary vitamin C requirements of juvenile eel to be 41.1, 41.2, 43.9 and 43.1 (mg kg-1 diet), respectively. These results indicated that the dietary vitamin $C$ requirement could range from 41.1 to $43.9 \mathrm{mg} \mathrm{kg}^{-1}$ diet in juvenile eel when L-ascorbyl-2-monophosphate was used as the dietary source of vitamin C. (Key Words : Vitamin C, L-ascorbyl-2-monophosphate (AMP), Growth Performance, Eel, Anguilla japonica)
\end{abstract}

\section{INTRODUCTION}

Vitamin C (ascorbic acid, AA) is a strong antioxidant that is capable of scavenging reactive oxygen species and can regenerate antioxidant molecules such as $\alpha$-tocopherol $(\alpha-\mathrm{T})$. Vitamin $\mathrm{C}$ thus protects against free radicals. Ascorbic acid acts as a cofactor in the enzymatic hydroxylation of proline residues of collagen and connective tissue in vertebrates. Numerous studies have shown that AA is an essential micronutrient required to maintain the physiological processes of certain animals,

\footnotetext{
* Corresponding Author: Sungchul C. Bai. Tel: +82-51-629-5916, Fax: +82-51-628-6873, E-mail: scbai@pknu.ac.kr

${ }^{2}$ Chungnam Fisheries Institute, Chungcheognam-do, Boryong 355-880, Korea.

${ }^{3}$ Department of Aquaculture and Aquatic Sciences, Kunsan National University, Kunsan 573-701, Korea.

${ }^{4}$ New Strategy Research Center, National Fisheries Research and Development Institute, Busan 408-15, Korea.

Received June 27, 2011; Accepted September 28, 2011
}

including most fish (Tolbert, 1979). Fish are unable to synthesize AA due to the lack of L-gulonolactone oxidase enzyme, which is necessary to convert L-gulonic acid to AA. Fish therefore require AA in their diets (Sato et al., 1976). L-ascorbic acid is unstable and most of its activity is lost during processing and storage due to exposure to high temperature, oxygen and light (Hilton et al., 1977; Lim and Lovell, 1978; Soliman et al., 1987). Consequently, the derivatives of the parent compound, which are more stable, are used in aqua feed. However, the bioavailability of these derivatives usually varies and is frequently lower than that of the parent compound. Hence, studies have been carried out to evaluate the availability of various derivatives of ascorbic acid in different species (Soliman et al., 1986; Wilson et al., 1989; Shiau and Hsu, 1995, 1999; Wang et al., 2003a, b). Interestingly, some of these derivatives have been shown to have similar bioavailability in fish. Wang et al. (2003a) found L-ascorbyl-2-monophosphate calcium (AMP-Ca) to exhibit antiscorbutic activity equal to that of L-ascorbyl-2-monophosphate-Na/Ca (AMP-Na/Ca) in Korean 
rockfish, Sebastes schlegeli. The quantitative requirements for dietary vitamin $\mathrm{C}$ have been determined in several cultured species, including finfish and crustaceans (NRC, 1993).

The eel, Anguilla japonica, is a freshwater fish, a traditional Asian food that is widely consumed in East Asia. This species is constantly increasing in popularity among seafood consumers, with a corresponding increase in production from the meager value of $75,214 \mathrm{mt}$ in 1984 to 262,769 mt in 2009 (FAO, 2010). Five major producers of this species are China, Japan, Korea, Malaysia and Taiwan. Although the dietary vitamin $\mathrm{C}$ requirement has been estimated in Japanese eel using L-ascorbic acid Ca as the source of vitamin C (Ren et al., 2005) this requirement could vary when other sources of vitamin C are used. Therefore, the purpose of this study was to re-evaluate the dietary vitamin $\mathrm{C}$ requirement in juvenile eel, $A$. japonica, based on growth performance and body composition by using L-ascorbyl-2-monophosphate as the vitamin C source.

\section{MATERIALS AND METHODS}

\section{Preparation of experimental diets}

Composition of the semi-purified basal diet is shown in Table 1 . Five experimental diets were prepared to contain 0 , 30, 60, 120 or 1,200 mg AMP kg-1 diet (dry matter basis, $\mathrm{DM}$ ) in the form of L-ascorbyl-2-monophosphate (AMP) by adding appropriate amounts of AMP pre-mixture (10 mg AMP $\mathrm{g}^{-1}$ cellulose). The actual ascorbic acid concentrations

Table 1. Composition of the basal diet for juvenile eel

\begin{tabular}{|c|c|}
\hline Ingredients & $\%$ of dry matter basis \\
\hline Casein $^{1}$ & 27.5 \\
\hline Defatted fish meal $^{2}$ & 27.5 \\
\hline Wheat flour ${ }^{3}$ & 11.3 \\
\hline Corn starch $^{3}$ & 16.0 \\
\hline Fish oil ${ }^{4}$ & 3.1 \\
\hline Corn oil ${ }^{5}$ & 6.2 \\
\hline Vitamin premix (Vitamin C-free) $^{6}$ & 3.0 \\
\hline Mineral premix ${ }^{7}$ & 3.0 \\
\hline Vitamin C premix ${ }^{8}$ & 0.0 \\
\hline Carboxymethylcellulose $^{1}$ & 2.4 \\
\hline \multicolumn{2}{|c|}{ 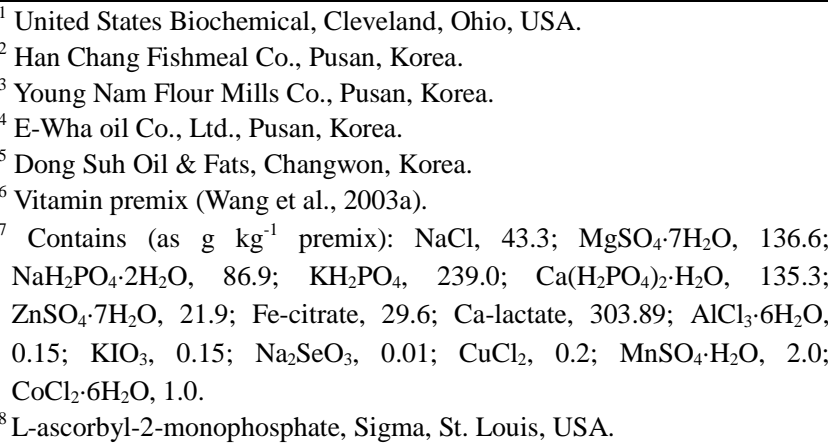 } \\
\hline
\end{tabular}

of the experimental diets were determined by high-pressure liquid chromatography (HPLC) to be 0 (AMP0), 24.1 (AMP24), 52.3 (AMP52), 107.9 (AMP108) and 1,137 (AMP1137) $\mathrm{mg} \mathrm{kg}^{-1}$ diet. In diets supplemented with ascorbic acid, equivalent amounts of cellulose were removed. The experimental diets were formulated to contain 50\% crude protein and $19.8 \mathrm{~kJ}_{\text {gross energy g }}{ }^{-1}$ diet (excluding indigestible gross energy). Fish meal was extracted four times by using $75-80^{\circ} \mathrm{C}$ hot ethanol (fish meal/ethanol $=1: 2$, W/V) before incorporation into the diet (Kosutarak et al., 1995). Vitamin-free casein and defatted fish meal were used as the main protein sources. Experimental diets were prepared by mixing the dry ingredients in an electric mixer, followed by the addition of oil and water. This mixture was formed into dough, and dry pellets were made by passing the dough through a screwtype pelleting machine and air drying the formed pellets for approximately $48 \mathrm{~h}$. After drying, the pellets were broken up, sieved into the proper pellet size, sealed and stored at $-20^{\circ} \mathrm{C}$ until use.

\section{Experimental fish and feeding trials}

Juvenile eel, Anguilla japonica, were obtained from Na-Ju, Korea. Prior to the start of the feeding trial, fish were fed with the basal diet for 4 weeks for acclimation to the semi-purified diet and to deplete possible body reserves of vitamin C. At the start of the experiment, fish were starved for $24 \mathrm{~h}$ and weighed after being anesthetized with ethylene glycol phenyl ether. The feeding trial was conducted in a recirculating system with a biofilter installed in a concrete water reservoir. All aquaria were equipped with the aeration system and water was heated by electric heaters in the concrete reservoir. Water temperature was maintained at $25 \pm 1.0^{\circ} \mathrm{C}$ (mean $\pm \mathrm{SD}$ ) and water flow rate was $1 \mathrm{~L} \mathrm{~min}^{-1}$. Experimental fish averaging $15.0 \pm 0.3 \mathrm{~g}$ (mean $\pm \mathrm{SD}$ ) were randomly distributed to each of 15 aquaria (60 L capacity) as groups of 20 fish. Each diet was fed to triplicate groups at a feeding rate of $3 \%$ of wet body weight, with the feed for each day divided in two parts and provided at two separate times. The feeding trial lasted for 12 weeks. Total fish weight per aquarium was determined every 4 weeks, and the amount of diet fed was adjusted accordingly. Dead fish were immediately removed and weighed, and the amount of feed for the tanks was fixed at the proper percentage of fish weight. Uneaten feed was collected from each tank by siphoning and dried in an oven at $70^{\circ} \mathrm{C}$ to a constant weight. Actual feed consumption was estimated as the difference in weight between the feed supplied and the uneaten feed removed by siphoning. The interior panels of the aquaria were scrubbed once per week in addition to the daily siphoning of feces to minimize algal and fungal growth, which could potentially provide vitamins. 
Table 2. Effects of the dietary vitamin C levels on growth performance of juvenile eel, Anguilla japonica, fed experimental diets for 12 weeks ${ }^{1}$

\begin{tabular}{|c|c|c|c|c|c|}
\hline & WG $(\%)^{2}$ & SGR $(\% / d)^{3}$ & $\mathrm{FE}(\%)^{4}$ & $\mathrm{PER}^{5}$ & Survival (\%) \\
\hline \multicolumn{6}{|c|}{ Vitamin C (L-ascorbyl-2-monophosphate, AMP mg kg-1 diet) } \\
\hline $\mathrm{AMP}_{0}$ & $68.2 \pm 5.22^{\mathrm{b}}$ & $0.74 \pm 0.04^{\mathrm{b}}$ & $48.0 \pm 7.66^{\mathrm{b}}$ & $0.96 \pm 0.15^{\mathrm{b}}$ & $83.3 \pm 7.64^{\mathrm{b}}$ \\
\hline $\mathrm{AMP}_{24}$ & $85.6 \pm 2.60^{\mathrm{ab}}$ & $0.88 \pm 0.02^{\mathrm{ab}}$ & $59.8 \pm 3.65^{\mathrm{ab}}$ & $1.20 \pm 0.07^{\mathrm{ab}}$ & $96.7 \pm 5.77^{\mathrm{a}}$ \\
\hline $\mathrm{AMP}_{52}$ & $98.0 \pm 6.84^{\mathrm{a}}$ & $0.98 \pm 0.05^{\mathrm{a}}$ & $65.3 \pm 4.56^{\mathrm{a}}$ & $1.31 \pm 0.09^{\mathrm{a}}$ & $96.7 \pm 5.77^{\mathrm{a}}$ \\
\hline $\mathrm{AMP}_{108}$ & $91.6 \pm 6.36^{\mathrm{a}}$ & $0.93 \pm 0.05^{\mathrm{a}}$ & $63.9 \pm 7.01^{\mathrm{ab}}$ & $1.28 \pm 0.14^{\mathrm{ab}}$ & $97.8 \pm 2.89^{\mathrm{a}}$ \\
\hline $\mathrm{AMP}_{1137}$ & $89.1 \pm 4.84^{\mathrm{ab}}$ & $0.91 \pm 0.04^{\mathrm{ab}}$ & $62.2 \pm 7.56^{\mathrm{ab}}$ & $1.24 \pm 0.15^{\mathrm{ab}}$ & $98.3 \pm 2.89^{\mathrm{a}}$ \\
\hline
\end{tabular}

${ }^{1}$ Values are means from triplicate groups of fish where the means in each column with a different superscript are significantly different $(\mathrm{p}<0.05)$.

${ }^{2}$ Weight gain $(\%)=(($ final wt. - initial wt. $) /$ initial wt. $) \times 100 .{ }^{3}$ Specific growth rate $(\%)=\left(\left(\log _{e}\right.\right.$ final wt.- $\log _{e}$ initial wt. $) /$ days $) \times 100$.

${ }^{4}$ Feed efficiency $(\%)=($ wet wt. gain/dry feed intake $) \times 100 .{ }^{5}$ Protein efficiency ratio = wet wt. gain/protein intake.

\section{Analyses and measurements}

Weight gain (WG), specific growth rate (SRG), feed efficiency (FE) and protein efficiency ratio (PER) were measured and calculated after each weighing. Samples of 20 fish at the beginning of the experiment and 6 fish per tank at the termination were collected and stored frozen at $-20^{\circ} \mathrm{C}$ for determination of proximate carcass composition. Proximate composition analyses of experimental diets and fish bodies were performed by the standard methods of AOAC (1995). Samples of diets and fish were dried to a constant weight at $105^{\circ} \mathrm{C}$ to determine moisture content. Ash was determined by incineration at $550^{\circ} \mathrm{C}$, crude lipid by soxhlet extraction using the Soxtec system 1046 (Tecator $\mathrm{AB}$, Hoganas, Sweden), and crude protein by the Kjeldahl method $(\mathrm{N} \times 6.25)$ after acid digestion. Vitamin $\mathrm{C}$ concentrations in experimental diets and carcasses of pooled fish (five fish per aquarium) were determined by high performance liquid chromatography (HPLC; Sykam, Eresing, German) with a UV detector at $254 \mathrm{~nm}$. All the analyses were conducted according to standard methods (AOAC, 1995).

\section{Statistical analysis}

All data were analyzed by one-way ANOVA to test for the effects of the dietary treatments. When a significant treatment effect was observed, a Least Significant Difference (LSD) test was used to compare means. Treatment effects were considered with the significance level at $\mathrm{p}<0.05$. Broken-line analysis (Robbins et al., 1979) was used to estimate the optimum dietary level of vitamin C. All statistical analyses were carried out by SAS version 9.0 software (SAS Institute, Cary, NC, USA).

\section{RESULTS AND DISCUSSION}

Weight gain (WG), specific growth rate (SGR), feed efficiency (FE), protein efficiency ratio (PER) and survival of juvenile eels fed the experimental diets for 12 weeks are shown in Table 2. Weight gain and SGR for fish fed AMP52 and AMP108 were significantly higher than those for fish fed the non-supplemented diet $(\mathrm{p}<0.05)$. However, there were no significant differences among fish fed AMP24, AMP52, AMP108 and AMP1137 or among those fed AMP0, AMP24 and AMP1137. Broken-line regression analysis on the basis of WG and SGR showed the dietary vitamin C requirements of juvenile eel to be 41.1 and $41.2 \mathrm{mg} \mathrm{kg}^{-1}$ diet, respectively (Figure 1A, B). Similarly, FE and PER of fish fed AMP52 were significantly higher than those of fish fed the diet without AMP supplementation $(p<0.05)$. However, there were no significant differences in these parameters among fish fed AMP24, AMP52, AMP108 and AMP1137 or among those fed AMP0, AMP24, AMP108 and AMP1137. Broken-line regression analysis on the basis of FE and PER showed the dietary vitamin $C$ requirements of juvenile eel to be 43.9 and $43.1 \mathrm{mg} \mathrm{kg}^{-1}$ diet, respectively (Figure 1C, D).

The above results indicated the essentiality of dietary vitamin C in juvenile eel. However, based on ANOVA of tested growth parameters, there seemed to be no benefits of increasing vitamin $C$ supplementation in diets beyond 24 mg AMP $\mathrm{kg}^{-1}$ diet, as fish fed any of the Vitamin Csupplemented diets had similar growth performance. Lin and Shiau (2005) observed the weight gain of juvenile grouper, Epinephelus malabaricus, to increase up to the requirement level of $45.3 \mathrm{mg} \mathrm{AA} \mathrm{kg}^{-1}$ diet, without further improvement with increasing supplementation. Similar results have been obtained in large yellow croaker, Pseudosciaena crocea (Ai et al., 2006). Unlike the fatsoluble vitamins, excess vitamin C causes little harm in fish. Conversely, elevated levels of vitamin $C$ have been shown to improve immune responses and disease resistance in various species (Durve and Lovell, 1982; Li and Lovell, 1985; Navarre and Halver, 1989; Hardie et al., 1991; Waagbo et al., 1993). Consequently, researchers have estimated the dietary vitamin $\mathrm{C}$ requirements for enhancement of non-specific immune responses and maintenance of survival to be higher than those determined by an analysis of growth performance (Lin and Shiau, 2005). In the present study, non-specific immunological 

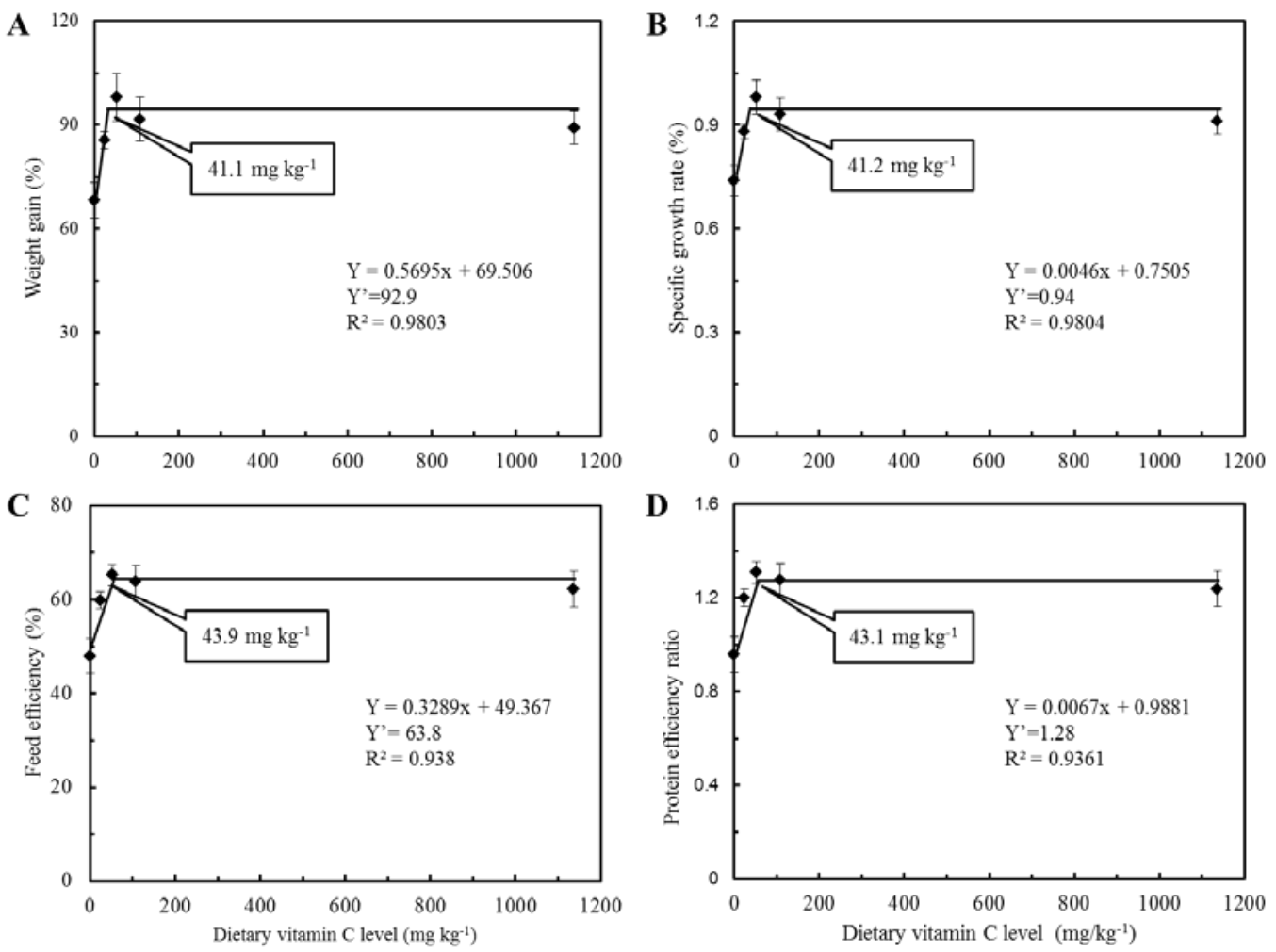

Figure 1. Broken-line analysis of (a) weight gain (WG), (b) specific growth rate (SGR), (c) feed efficiency (FE) and (d) protein efficiency ratio (PER) of juvenile eels fed diets containing different levels of vitamin $\mathrm{C}$ for 12 weeks. Values on the X-axis are the vitamin $\mathrm{C}$ levels in experimental diets. Values are means $\pm \mathrm{SD}$ of 3 replicates.

response parameters were not tested, as fish were too small for organs to be extracted easily.

The requirements above seem to be low when compared to results obtained in some teleosts and aquatic invertebrates. Wang et al. (2003a) found the dietary vitamin $\mathrm{C}$ requirement in Korean rockfish, Sebastes schlegeli, to be $106 \mathrm{mg} \mathrm{AA} \mathrm{kg}^{-1}$ diet based on the pooled weight gain of fish fed AMP-Na/Ca and AMP-Ca. Okorie et al. (2008) reported the dietary vitamin $\mathrm{C}$ requirement in sea cucumber, Apostichopus japonicus, to be $100-105.3$ mg AA kg-1 diet. The requirement as determined based on broken-line analysis of WG is comparable to values obtained in common carp, Cyprinus carpio (45 mg AA kg-1 diet) (Gouillou-Coustans et al., 1998) and in grouper, Epinephelus malabaricus (45.3 mg AA kg-1 diet) (Lin and Shiau, 2005), but higher than the minimum value of $27 \mathrm{mg}$ AA kg-1 diet in eel, Anguilla japonica (Ren et al., 2005). Ren et al. (2005) reported a minimum requirement of $27 \mathrm{mg}$ AA $\mathrm{kg}^{-1}$ diet without stating an upper limit. Although no significant differences were recorded above this minimum level, SGR continued to increase numerically up to the maximum supplementation level in their study. Furthermore, the aforementioned study was done using L-ascrobic acid $\mathrm{Ca}$ as the vitamin C source while L-ascorbyl-2monophosphate was used in our study. Any differences could be attributed to the vitamin $C$ source. But if broken line analysis had been done on the data in the previous study, the requirements might be similar, suggesting no differences in the availability of these vitamin C sources.

Survival of fish fed the AMP-supplemented diets was significantly higher than that of fish that did not receive AMP supplementation $(\mathrm{p}<0.05)$. However, there were no significant differences in survival of fish fed all the supplemented diets. Vitamin C supplementation has been reported to improve immune resistance and survival of various species of fish. Lin and Shiau (2005) found survival of grouper, Epinephelus malabaricus, fed at least 14 mg AA kg-1 diet to be significantly higher than that of fish fed $3 \mathrm{mg} \mathrm{AA} \mathrm{kg}{ }^{-1}$ diet or less. Similarly, Ai et al. (2006) observed the survival of large yellow croaker, Pseudosciaena crocea, fed $23.8 \mathrm{mg} \mathrm{AA} \mathrm{kg}{ }^{-1}$ diet (in the form of L-ascorbyl-2-polyphosphate) to be significantly higher than that of fish fed non-supplemented diets or those fed diets containing $12.2 \mathrm{mg} \mathrm{AA} \mathrm{kg}^{-1}$ diet. However, Okorie et al. (2008) observed no clear trend in survival of sea cucumber, Apostichopus japonicus, fed graded levels of L-ascorbyl-2-monophosphate and Ren et al. (2005) found no significant differences in survival of eel, $A$. japonica, fed different levels of L-ascorbic acid-Ca.

Whole-body proximate composition and vitamin C 
Table 3. Whole-body proximate composition and vitamin C concentrations of juvenile eel, Anguilla japonica, fed experimental diets for $12 \mathrm{wk}^{1}$

\begin{tabular}{|c|c|c|c|c|c|}
\hline & Moisture & Ash & Protein & Lipid & $\begin{array}{c}\text { Vitamin C } \\
\left(\mu \mathrm{g} \mathrm{g}^{-1}\right)\end{array}$ \\
\hline \multicolumn{6}{|c|}{ Vitamin C (L-ascorbyl-2-monophosphate, AMP mg kg-1 diet) } \\
\hline $\mathrm{AMP}_{0}$ & 61.0 & 3.2 & 17.1 & 44.5 & $\mathrm{ND}^{3}$ \\
\hline $\mathrm{AMP}_{24}$ & 62.4 & 3.2 & 16.3 & 46.7 & $16.4^{\mathrm{c}}$ \\
\hline $\mathrm{AMP}_{52}$ & 62.5 & 3.3 & 18.2 & 46.3 & $20.8^{\mathrm{c}}$ \\
\hline $\mathrm{AMP}_{108}$ & 63.3 & 3.1 & 18.4 & 46.6 & $46.5^{\mathrm{b}}$ \\
\hline $\mathrm{AMP}_{1137}$ & 62.8 & 3.4 & 18.4 & 46.6 & $78.3^{\mathrm{a}}$ \\
\hline Pooled SEM ${ }^{2}$ & 0.58 & 0.09 & 0.42 & 0.42 & 9.13 \\
\hline
\end{tabular}

${ }^{1}$ Values are means from triplicate groups of fish where the means in each column with a different superscript are significantly different ( $<<0.05$ ).

${ }^{2}$ Pooled standard error of mean: SD $\sqrt{n} \cdot{ }^{3}$ Not detectable.

concentrations of fish fed the experimental diets are shown in Table 3. There were no significant differences in moisture, protein, lipid and ash of fish fed any of the experimental diets. No vitamin C was detected in fish fed AMP0. Vitamin C levels in fish fed AMP1137 were significantly higher than in fish fed the other diets $(\mathrm{p}<0.05)$. Vitamin $\mathrm{C}$ levels in fish fed AMP108 were significantly higher than those in fish fed AMP24 and AMP52 $(\mathrm{p}<0.05)$. However, there were no significant differences in vitamin $\mathrm{C}$ concentrations among fish fed AMP24 and AMP52. Whole-body and tissue vitamin $\mathrm{C}$ concentration increased with dietary vitamin content, a trend observed in various species (Wang et al., 2002, 2003a, b; Lin and Shiau, 2005).

In summary, the dietary vitamin $\mathrm{C}$ requirement in juvenile eel, A. japonica, ranges from 41.1 to $43.9 \mathrm{mg} \mathrm{kg}^{-1}$ diet. This conclusion is based on broken-line regression analysis of WG, SGR, FE and PER when L-ascorbyl-2monophosphate was used as the dietary vitamin $C$ source under the present experimental conditions.

\section{ACKNOWLEDGEMENTS}

This work was supported by the Korea Research Foundation Grant funded by the Korean Government (KRF2008-313-F00085) and partially supported by a grant (RP2011-AQ-096) from the National Fisheries Research and Development Institute (NFRDI).

\section{REFERENCES}

Ai, Q. H., K. S. Mai, B. P. Tan, W. Xu, W. B. Zhang, H. M. Ma and Z. G. Liufu. 2006. Effects of dietary vitamin C on survival, growth, and immunity of large yellow croaker, Pseudosciaena crocea. Aquaculture 261:327-336.

AOAC. 1995. Official methods of analysis of 16th edn. Association of Official Analytical Chemists, Arlington, Virginia, USA.

Durve, V. S. and R. T. Lovell. 1982. Vitamin C and disease resistance in channel catfish, Ictalurus punctatus. Can. J. Fish Aquat. Sci. 39:948-951.
FAO (Food and Agriculture Organization) 2010. Fishery information, data and statistics website. Aquaculture production, 1984-2009.

Gouillou-Coustans, M. F., P. Bergot and S. J. Kaushik. 1998. Dietary ascorbic acid needs of common carp, Cyprinus carpio larvae. Aquaculture 161:453-461.

Hardie, L. J., T. C. Fletcher and C. J. Secombes. 1991. The effect of dietary vitamin $\mathrm{C}$ on the immune response of the Atlantic salmon, Salmo salar L. Aquaculture 95:201-214.

Hilton, J. W., C. Y. Cho and S. J. Slinger. 1977. Evaluation of ascorbic acid status of rainbow trout, Salmo gairdneri. J. Fish. Res. Board Can. 34:2207-2210.

Kosutarak, P., A. Kanazawa, S. Teshima and S. Koshio. 1995. Interactions of L-ascorbyl-2-phosphate-Mg and n-3 highly unsaturated fatty acids on Japanese flounder juveniles. Fish. Sci. 61:860-866.

Li., Y. and R. T. Lovell. 1985. Elevated levels of dietary ascorbic acid increase immune responses in channel catfish. J. Nutr. 115:123-131.

Lim, C. and R. T. Lovell. 1978. Pathology of the vitamin C deficiency syndrome in channel catfish, Ictalurus punctatus. J. Nutr. 108:1137-1146.

Lin, M. F. and S. Y. Shiau. 2005. Dietary L-ascorbic acid affects growth, nonspecific immune responses and disease resistance in juvenile grouper, Epinephelus malabaricus. Aquaculture 244:215-221.

NRC (National Research Council Nutrient Requirements of Fish). 1993. National Academic Press, Washington, DC, USA.

Navarre, O. and J. E. Halver. 1989. Disease resistance and humoral antibody production in rainbow trout fed high levels of vitamin C. Aquaculture 79:207-221.

Okorie, O. E., S. H. Ko, S. G. Go, S. H. Lee, J. Y. Bae, K. M. Han and S. C. Bai. 2008. Preliminary study of the optimum dietary ascorbic acid level in sea cucumber, Apostichopus japonicus (Selenka). J. World Aquac. Soc. 39(6):758-765.

Ren, T., S. Koshio, S. Teshima, M. Ishikawa, M. Alam, A. Panganiban, Y. Y. Moe, T. Kojima and H. Tokumitsu. 2005. Optimum dietary level of L-ascorbic acid for Japanese eel, Anguilla japonica. J. World Aquac. Soc. 36(4):437-443.

Robbins, K. R., H. W. Norton and D. H. Baker. 1979. Estimation of nutrient requirements from growth data. J. Nutr. 109:17101714.

Sato, P., M, Nishikimi and S. Udenfriend. 1976. Is L- 
gulonolactone-oxidase the only enzyme missing in animals subject to scurvy? Biochem. Biophys. Res. Commun. 71:293299.

Shiau, S. Y. and T. S. Hsu. 1995. L-Ascorbyl-2-sulfate has equal antiscorbutic activity as L-ascorbyl-2-monophosphate for tilapia, Oreochromis niloticus $\times O$. aureus. Aquaculture 133:147-157.

Shiau, S. Y. and T. S. Hsu. 1999. Quantification of vitamin C requirement for juvenile hybrid tilapia, Oreochromis niloticus $\times$ Oreochromis aureus, with L-ascorbyl-2-monophosphate-Na and L-ascorbyl-2-monophosphate-Mg. Aquaculture 175:317326.

Soliman, A. K., K. Jauncey and R. J. Roberts. 1986. The effect of varying forms of dietary ascorbic acid on the nutrition of juvenile tilapias, Oreochromis niloticus. Aquaculture 52:1-10.

Soliman, A. K., K. Jauncey and R. J. Roberts. 1987. Stability of Lascorbic acid (vitamin $\mathrm{C}$ ) and its forms in fish feeds during processing, storage and leaching. Aquaculture 60:73-83.
Tolbert, B. M. 1979. Ascorbic acid metabolism and physiological function. Int. J. Vitam. Nutr. Res. 19:127-142.

Waagbo, R., J. Glette, E. Raa-Nilsen and K. Sandnes. 1993. Dietary vitamin C, immunity and disease resistance in Atlantic salmon, Salmo salar. Fish Physiol. Biochem. 12:61-73.

Wang, X. J., K. W. Kim and S. C. Bai. 2002. Effects of different dietary levels of L-ascorbyl-2-polyphosphate on growth and tissue vitamin $\mathrm{C}$ concentrations in juvenile olive flounder, Paralichthys olivaceus. Aquacult. Res. 33:261-267.

Wang, X. J., K. W. Kim and S. C. Bai. 2003a. Comparison of Lascorbyl-2-monophosphate-Ca with L-ascorbyl-2-monophosphate$\mathrm{Na} / \mathrm{Ca}$ on growth and tissue ascorbic acid concentrations in Korean rockfish, Sebastes schlegeli. Aquaculture 225:387-395.

Wang, X. J., K. W. Kim, S. C. Bai, M. D. Huh and B. Y. Cho. 2003b. Effects of the different levels of dietary vitamin $C$ on growth and tissue ascorbic acid changes in parrot fish, Oplegnathus fasciatus. Aquaculture 215:203-211.

Wilson, R. P., W. E. Poe and E. H. Robinson. 1989. Evaluation of L-ascorbyl-2-polyphosphate (C2PP) as a dietary ascorbic acid source for channel catfish. Aquaculture 81:129-136. 